\title{
Revised and short versions of the pseudoscientific belief scale
}

Article published in Applied Cognitive Psychology

https://doi.org/10.1002/acp.3811

\author{
Angelo Fasce ${ }^{1}$, Diego Avendaño ${ }^{2}$, and Jesús Adrián-Ventura ${ }^{3}$ \\ ${ }^{1}$ University of Valencia - angelofasce@ hotmail.com. \\ 2 University of Pamplona. \\ ${ }^{3}$ Jaume I University.
}

In this article, we develop the revised and short versions of the pseudoscientific belief scale through two empirical studies $(N=4154)$. This revision is motivated by the excessive length of the scale, as well as by consistent observations of poor item loadings across several studies. Exploratory factor analysis in Study 1 revealed eleven dispensable items, resulting in a 19-item revised form, whereas in Study 2 we constructed a short 8item form. Confirmatory factor analysis revealed unidimensional factor structures for both scales, exhibiting excellent psychometric properties in relation to factor structure, item loadings, internal consistency and convergent validity with paranormal beliefs, conspiracy theories and need for uniqueness. Whereas the original scale provides reliable indices, we encourage the use of the se improved versions to measure pseudoscientific beliefs in the context of socio-psychological studies.

Key words: Pseudoscientific beliefs scale, pseudoscience, paranormal beliefs, conspiracy theories, need for uniqueness. 
Revised and short versions of the pseudoscientific belief scale

Pseudoscience is usually defined as cognitions involving radical epistemic misconduct and science mimicry (Hansson, 2009; Fasce, 2020), with two major forms: pseudo-theory promotion and science denial (Hansson, 2017; Fasce \& Picó, 2019a). On one hand, pseudo-theory promotion is based on complicated doctrinal content, which often includes flawed mechanistic explanations and insubstantial conceptual schemesfor example, morphic fields, German new medicine, cellular memories, and chiropractic. On the other hand, science deniers tend to concoct false controversies, motivated by their enmity towards a well-established scientific theory-for example, chemophobia and denial of climate change, GMOs and vaccination.

Pseudoscientific movements have received substantial and multidisciplinary attention, highlighting their harmful implications and enduring popularity, but also their associated social and cognitive variables. Psychological research has positively linked anti-scientific beliefs, such as pseudoscience, with authoritarianism (Fasce, AdriánVentura, \& Avendaño, 2020), overreliance in intuitive thinking (Pennycook, Cheyne, Seli, Koehler, \& Fugelsang, 2012), ontological confusions (Lindeman, SvedholmHakkinen, \& Lipsanen, 2015), poor scientific literacy (Fasce \& Picó, 2019b), pseudoprofound bullshit receptivity (Pennycook, Cheyne, Barr, Koegler \& Fugelsang, 2015), and causalillusions (Torres, Barberia, \& Rodríguez-Ferreiro, 2020). Furthermore, interest in pseudoscience has increased in recent times, due to the massive spread of disinformation during the COVID-19 pandemic (e.g., Escolà-Gascón, Marín, Rusiñol, \& Gallifa, 2020). 
The Pseudoscientific Belief Scale (PSEUDO; Fasce \& Picó, 2019a) is the first validated psychometric tool for the measurement of pseudoscience as a comprehensive construct - analogously to what has been done previously in relation to other forms of anti-scientific beliefs, such as paranormal and conspiracy theories (Tobacyk, 2004; Brotherton, French, \& Pickering, 2013). The scale has been successfully used in several studies within a wide range of domains, such as the relation of pseudoscientific beliefs to scientific literacy (Fasce \& Picó, 2019b), authoritarianism (Fasce, Adrián-Ventura, \& Avendaño, 2020), alternative psychotherapies (Fasce \& Adrián-Ventura, 2021), and intergroup threat (Fasce, Adrián-Ventura, Lewandowsky, \& van der Linden, 2021).

Due to this intensive and iterative use, we have detected two shortcomings in the original scale. Firstly, the original 30 -item version may turn out to be too time-consuming when data recollection processes involve time constraints. This issue constitutes an important limitation for the scientific use of the original scale, especially in studies in which pseudoscientific beliefs are an independent variable. Secondly, we have detected that some items included in the original scale consistently show weak loadings. In this paper, we address these issues by developing a revised version of the scale, eliminating poor items, and a short version, based on the most representative of them. For this, we report two studies in which we carry out exploratory and confirmatory factor analyses, as well as assess the convergent validity of the revised and short versions of the scale.

\section{Study 1: Development of the revised form of PSEUDO}

For the first study, we recruited a sample of 3183 Spanish-speaking participants through social media (Facebook and Twitter), for the online fulfillment of the set of scales 
via Google Forms. No rewards were offered in exchange and all participants gave their informed consent prior to their inclusion in the study. $1755(55 \%)$ were men and 1428 $(45 \%)$ were women, with an average age of $39.40(S D=10.50) .1195(38 \%)$ had preuniversity education and $1988(62 \%)$ had university education.

Study 1 was aimed at conducting an exploratory factor analysis in order to reduce our data variables, producing a revised version of the scale. Thus, for this study we included the original 30-item version of PSEUDO $(\alpha=0.89$; Likert $1-5 ; M=56.75, S D$ $=16.49$ ).

\section{Construction of the revised form of PSEUDO}

Exploratory factor analysis (EFA) was performed by IBM SPSS Statistics for Windows, Version 25.0 (Armonk, NY: IBM Corp.). Due to the unifactorial nature of the original 30-item scale, we suggested a one-factor solution using maximum likelihood estimation ${ }^{1}$. EFA revealed a successful factorial solution and sampling adequacy (KMO $=0.94$; Bartlett's sphericity test: $\left.\chi^{2}(435)=26280.50, p<0.001\right)$, explaining $25 \%$ of the variance.

Subsequently, item loadings obtained from the EFA were used for the development of the revised version of the scale (PSEUDO-R). Meaningful loadings were assessed using the following cut-off criteria: 0.32 (poor), 0.45 (fair), 0.55 (good), 0.63 (very good), and 0.71 (excellent; Tabachnick \& Fidell, 2007). We selected those items with a fair factor loading (above 0.45). The resulting scale consisted of 19 items, which were tested in subsequent analysis. All these items are displayed in Table 1 . The internal

\footnotetext{
${ }^{1}$ Even though we mentioned, at the beginning of this article, the theoreticaldistinction between pseudo theory promotion and science denial, the results obtained by Fasce and Picó (2019a) suggested that, in psychological terms, both types of pseudoscience constitute a single factor. This issue wa s carefully a naly sed in the original validation of PSEUDO.
} 
consistency of PSEUDO-R was excellent $(\alpha=0.90 ; M=37.37, S D=13.31)$, whereas the correlation with the original PSEUDO scale was extremely high $(r=0.97, p<0.001)$.

\section{Study 2: Testing the factor structure, short version, and convergent validity}

For the second study, we recruited a sample composed of 971 Spanish-speaking participants through social media (Facebook and Twitter). No rewards were offered in exchange and all participants gave their informed consent prior to their inclusion in the study. $576(59 \%)$ were men and $395(41 \%)$ were women, with an average age of 35.32 $(S D=12.38) ; 212(22 \%)$ had pre-university education and $759(78 \%)$ had university education; 805 (83\%) self-identified as non-religious (atheist or agnostic), while 166 (17\%) self-identified as religious (practicing or non-practicing).

This study was aimed at confirming the factorial structure of the revised version of PSEUDO in addition to further develop a reduced, short form. To this end, we used the resulting 19-item PSEUDO-R version $(\alpha=0.92$; Likert $1-5 ; M=37.93, S D=13.83)$, previously developed in Study 1. Additionally, in order to assess the convergent validity of the revised and short versions of the scale, we included a 26 -item scale on Paranormal Beliefs (Tobacyk, 2004; Likert 1-7; $\alpha=0.94 ; M=44.85, S D=21.97$ ), a 15-item scale on Conspiracy Beliefs (Brotherton, French, \& Pickering, 2013; Likert 1-5; $\alpha=0.94 ; M=$ 34.43, $S D=13.91$ ), and a 4-item scale on Need for Uniqueness (Lynn \& Harris, 1997; Likert $1-5 ; \alpha=0.80 ; M=10.65, S D=3.09)$. 


\section{Confirmation of the factor structure of PSEUDO-R}

Confirmatory factor analysis (CFA) was performed by means of IBM SPSS Amos, Version 23.0 (Chicago, IL: IBM SPSS). Using maximum likelihood estimation, we investigated if a unique latent variable (or "factor") satisfactorily explained the variability observed within PSEUDO-R by analyzing the item-factor correlation. For this purpose, we took into consideration the most commonly used cut-off values for acceptable goodness of fit indices: Comparative Fit Index (CFI) and Tucker-Lewis Index (TLI) close to 0.95 or greater, Root Mean Square Error of Approximation(RMSEA) close to 0.06 or below, and Standardized Root Mean Square Residual (SRMR) close to 0.08 or below (Brown, 2015). Although we report the chi-square test, it should be noted that its sensitivity to sample size of ten makes it prone to reject valid models based on the detection of any trivial misspecification, thus increasing type II error (Saris, Satorra, \& van der Veld, 2009)—-hence, we address it with caution.

The results from the CFA confirmed a one-factor structure for PSEUDO-R, analogous to that of the original scale, with excellent fit indices: $\chi^{2}(124)=222.26, p<$ 0.001; $\mathrm{CFI}=0.99, \mathrm{TLI}=0.98 ; \mathrm{RMSEA}=0.03(\mathrm{CI}: 0.022-0.035) ; \mathrm{SRMR}=0.02$. The resulting factor loadings are displayed in Table 1. 
Table 1

Type of pseudoscience, item contents, means, standard deviations, and item loadings of the revised version of the pseudoscientific belief scale.

\begin{tabular}{|c|c|c|c|}
\hline Pseudoscience & Item content & $M(S D)$ & Loa ding \\
\hline Body memory & $\begin{array}{l}\text { All the cells of our body store memories (cellular memories), ours or of our } \\
\text { ancestors }\end{array}$ & $2.32(1.39)$ & 0.66 \\
\hline Morphic fields & $\begin{array}{l}\text { The collectivememory inherited and shared by the organisms belonging to the same } \\
\text { species ('morphic field' or also 'morphic resonance') explains several biological } \\
\text { phenomena }\end{array}$ & $2.44(1.31)$ & 0.64 \\
\hline Quantum quackery & $\begin{array}{l}\text { Quantum mechanics has greatimplications in the explanation of consciousness and/or in } \\
\text { the trea tment of diseases }\end{array}$ & $2.26(1.14)$ & 0.61 \\
\hline $\begin{array}{l}\text { Osteopathy and } \\
\text { chiropractic }\end{array}$ & Osteopathy and/or chiropractic are scientifically backed branches of physiotherapy & $2.05(1.18)$ & 0.67 \\
\hline Reflexology & $\begin{array}{l}\text { There are areas of our body surface, such as the feet, hands and/or ears in which we } \\
\text { find representations of our entire anatomy }\end{array}$ & $1.89(1.20)$ & $\mathbf{0 . 8 0}$ \\
\hline Acupuncture & $\begin{array}{l}\text { The theoretical basis of a cupuncture is incongruent with current knowledgeabout human } \\
\text { anatomy }(\mathrm{R})\end{array}$ & $2.25(1.30)$ & 0.44 \\
\hline Law of attraction & $\begin{array}{l}\text { It is a proven fact that the enthusia stic repetition of desires or a sking them to the universe } \\
\text { (la w of attraction) could cause them to come true }\end{array}$ & $1.36(0.84)$ & 0.62 \\
\hline Intelligent design & $\begin{array}{l}\text { While it is true that evolution is a fact, there areissues that require an intelligent } \\
\text { intervention to be explained }\end{array}$ & $1.78(1.23)$ & 0.65 \\
\hline Parapsychology & $\begin{array}{l}\text { It has been scientifically proven that some people have extrasensory abilities (such } \\
\text { as telepathy or precognition) }\end{array}$ & $1.56(0.95)$ & 0.71 \\
\hline $\begin{array}{l}\text { Emotional } \\
\text { carcinogenesis }\end{array}$ & $\begin{array}{l}\text { Due to well demonstrated biological reasons, negative emotions and unsolved } \\
\text { conflicts or traumas increase the probability of having cancer }\end{array}$ & $1.84(1.16)$ & 0.66 \\
\hline $\begin{array}{l}\text { Neuro-linguistic } \\
\text { programming }\end{array}$ & Neuro-linguistic programming (NLP) is a ccepted as part of psychology & $2.41(1.13)$ & 0.59 \\
\hline Psychoanaly sis & The main ideas of psychoanalysis are supported by scientific evidence & $2.11(1.13)$ & 0.56 \\
\hline Blood type diet & Food should be chosen a ccording to the blood group of each person & $1.48(0.87)$ & 0.57 \\
\hline Pseudocosmetics & The use of stem cells and/or DNA improves the effectiveness of facial creams & $1.96(1.09)$ & 0.58 \\
\hline GMOs opposition & GMOs are medically a nd ecologically safe $(\mathrm{R})$ & $2.35(1.31)$ & 0.56 \\
\hline Pseudoarcheology & $\begin{array}{l}\text { There is archaeological evidence of ancient contacts with 'astronauts' or 'space } \\
\text { visitors' (for example, in cultures such as Sumerian, Egyptian, Maya or Nazca) }\end{array}$ & $1.61(1.03)$ & 0.71 \\
\hline Magnet therapy & $\begin{array}{l}\text { It is demonstrated that, in some contexts and cases, being exposed to magnetic fields is } \\
\text { positive for health }\end{array}$ & $2.02(1.14)$ & 0.49 \\
\hline Chemophobia & Many of the pesticides and additives used by the food industry are unsafe & $2.95(1.42)$ & 0.59 \\
\hline Antivaccination & Vaccines are unsafe, some of them cause diseases such as autism & $1.28(0.79)$ & 0.46 \\
\hline
\end{tabular}

Note: Means, standard deviations, and factor loadings were obtained from the CFA conducted in Study 2. All the 19 items included in Study 2 were previously extracted from the EFA performed in Study 1. Items in bold $=$ Short version. $(\mathrm{R})=$ Reversed encoded. 


\section{Construction of the short version}

On the basis of the CFA described above, we also selected those items with a very good factor loading, above 0.63 - as described in the widely used cut-off criteria established by Tabachnick and Fidell (2007)—, which resulted in a short 8-item version of the scale (PSEUDO-S; these items are displayed in bold in Table 1). CFA using maximum likelihood estimation also revealed excellent fit indices for the one-factor structure in the short form: $\chi^{2}(11)=12.77, p=0.31 ; \mathrm{CFI}=0.99, \mathrm{TLI}=0.99 ; \mathrm{RMSEA}=$ 0.01 (CI: $0.000-0.037)$;RMR $=0.01$. Moreover, PSEUDO-S showed good internal consistency $(\alpha=0.88 ; M=15.50, S D=7.00)$ and a very strong correlation with PSEUDO$\mathrm{R}(r=0.96, p<0.001)$.

\section{Convergent validity}

To assess the convergent validity of PSEUDO-R and PSEUDO-S, we carried out three predictions based on well-established background knowledge:

1) Based on Lobato, Mendoza, Sims, and Chin, (2014), we predicted that pseudoscientific beliefs are higher among people self-identified as religious.

2) Based on Lobato, Mendoza, Sims, and Chin (2014), Lewandowsky, Cook, and Lloyd (2018), and Fasce and Picó (2019a), we predicted that pseudoscientific beliefs are strongly and positively correlated to other forms of anti-scientific doctrines, such as paranormal and conspiracy theories.

3) Based on previous findings on conspiracy theories (Imhoff \& Lamberty, 2017; Lantian, Muller, Nurra, \& Douglas, 2017), we predicted that pseudoscientific beliefs are weakly and positively related to need for uniqueness. 
In this third prediction, intended to be riskier than the two previous ones, we extrapolated the rationale offered by Imhoff and Lamberty (2017), and Lantian, Muller, Nurra, and Douglas (2017) regarding conspiracy theories. Under this in terpretation, as a dispositionally high or a situationally enhanced need for uniqueness tend to motivate people to agree more with unpopular, minority opinions (e.g., Imhoff \& Erb, 2009), these individuals would satisfy their desire to be unique, true seekers of hidden, with the adoption of a conspiracy worldview. In our view, this theoretical background can be extrapolated to pseudoscientific doctrines, which also tend to be presented as "alternative knowledge" within highly motivated reference groups (Kahan, 2016)—moreover, the prototypical form of intergroup representation that lies at the root of conspiracy theories also plays a pivotal role in pseudoscientific doctrines (e.g., Jolley \& Douglas, 2014; Uscinski, Douglas, \& Lewandowsky, 2017).

Table 2

Correlation matrix between the variables included in Study 2.

\begin{tabular}{llllll}
\hline & 1 & 2 & 3 & 4 & 5 \\
\hline PSEUDO-R & - & $0.96^{*}$ & $0.69^{*}$ & $0.71^{*}$ & $0.15^{*}$ \\
PSEUDO-S & & - & $0.70^{*}$ & $0.69^{*}$ & $0.14^{*}$ \\
Paranormal Beliefs & & & - & $0.57^{*}$ & $0.18^{*}$ \\
Conspiracy Beliefs & & & - & $0.14^{*}$ \\
Need for Uniqueness & & & & \multicolumn{2}{l}{-} \\
\hline
\end{tabular}

Note: All values survived the Bonferroni correction at the $p<0.05$ threshold. $*=p<$ 0.001

As expected by our first prediction, we found that self-identified religious participants $(M=48.83, S D=12.50)$ had higher levels of endorsement of pseudoscience than non-religious participants $(M=35.68, S D=12.50)$, as measured by PSEUDO-R $[t$ 
$(216.15)=-10.69, p<0.001, d=-0.95 ; \mathrm{CI}:-15.31,-10.99]^{2}$. In addition, as can be seen from Table 2, correlation analyses conducted in order to test our second and third predictions were also in line with our expectations: PSEUDO-R showed to be strongly correlated to Paranormal Beliefs $(r=0.69 ; p<0.001)$ and Conspiracy Beliefs $(r=0.71$; $p<0.001)$, as well as weakly associated with Need for Uniqueness $(r=0.15 ; p<0.001)$, with PSEUDO-S showing an analogous nomological network. These results reveal the satisfactory convergent validity of these improved forms of the scale.

\section{Concluding remarks}

We would like to remark on some limitations of the reported results. In the first place, both samples were composed by a higher number of university-educated and nonreligious participants, therefore these asymmetries should be taken into consideration in the future to assess if they affected our results. In the second place, as the prevalence of pseudoscientific beliefs varies from one culture to another (e.g., endorsement of intelligent design may be quite low in non-Christian populations, acupuncture belief may be held primarily by people from East-Asian countries, etc.), the cross-cultural validity of these results should be addressed with caution. Lastly, in the current form of PSEUDO$\mathrm{R}$, it cannot discriminate people who intentionally disbelieve in a pseudoscientific doctrine from those who disagree because they don't have sufficient knowledge about the subject - a limitation shared with the majority of scales on beliefs, derived from asking

\footnotetext{
2 Besides this predictable socio-demographic difference, using PSEUDO-R, we a lso found interesting exploratory results regarding gender [more pseu doscientific beliefs a mong women $(M=41.46, S D=$ $14.48)$ than men $(M=35.51, S D=12.83): t(778.07)=-6.59, p<0.001, d=-0.43 ; C I:-7.69,-4.22]$; and education [more pseudoscientific beliefs a mong non-university educated participants $(M=41.92, S D=$ 13.92) than university-educated participants $(M=36.82, S D=13.61): t(969)=4.80, p<0.001, d=0.37$; CI: 3.01, 7.19].
} 
participants' agreement on the specific content. Accordingly, psychologists and social scientists using this scale might not implicitly assume that all participants have sufficient knowledge of all domains.

We have developed the revised and short versions of the pseudoscientific belief scale through two studies, which exhibit adequate psychometric properties, such as high item loadings and internal consistency, as well as proper convergent validity. The main advantage of these improved versions lies in their capacity to provide faster measurement of pseudoscientific beliefs in social-psychological studies, retaining the positive characteristics of the original scale. We recommend the use of these improved versions of the scale to other researchers interested in the study of pseudoscientific beliefs.

\section{References}

Brotherton, R., French, C., \& Pickering, A. (2013). Measuring belief in conspiracy theories: The generic conspiracist beliefs scale. Frontiers in Psychology, 4, 279. doi: 10.3389/fpsyg.2013.00279

Brown, T. (2015). Confirmatory factor analysis for applied research. New York: Guilford.

Escolà-Gascón, A., Marín, F., Rusiñol, J., \& Gallifa, J. (2020). Pseudoscientific beliefs and psychopathological risks increase after COVID-19 social quarantine. Globalization and Health, 16, 72. doi: 10.1186/s12992-020-00603-1

Fasce, A. (2020). Are Pseudosciences Like Seagulls? A Discriminant Metacriterion Facilitates the Solution of the Demarcation Problem. International Studies in the Philosophy of Science, 33(4), 617-628. doi: 10.1080/02698595.2020.1767891 
Fasce, A., \& Adrián-Ventura, J. (2021). Who demands alternative psychotherapies? A psychological inquiry. Under review.

Fasce, A., \& Picó, A. (2019a). Conceptual foundations and validation of the Pseudoscientific Belief Scale. Applied Cognitive Psychology, 33(4), 617-628. doi: 10.1002/acp.3501

Fasce, A., \& Picó, A. (2019a). Science as a Vaccine. The Relation between Scientific Literacy and Unwarranted Beliefs. Science \& Education, 28(1-2), 109-125. doi: $10.1007 / \mathrm{s} 11191-018-00022-0$

Fasce, A., Adrián-Ventura, J., \& Avendaño, D. (2020). Do as the Romans do: On the authoritarian roots of pseudoscience. Public Understanding of Science, 29(6), 597613. doi: $10.1177 / 0963662520935078$

Fasce, A., Adrián-Ventura, J., Lewandowsky, S., \& van der Linden, S. (2021). Science through a tribal lens: A group-based account of polarization over scientific facts. Under review.

Hansson, SO. (2009). Cutting the Gordian Knot of Demarcation. International Studies in the Philosophy of Science, 23(3), 237-243. doi: 10.1080/02698590903196007

Hansson, SO. (2017). Science denial as a form of pseudoscience. Studies in History and Philosophy of Science, Part A. 63, 39-47. doi: 10.1016/j.shpsa.2017.05.002

Henrich, J., Heine, S., \& Norenzayan, A. (2010). The weirdest people in the world?. Behavioral and Brain Sciences, 33(2-3), 61-83. doi: 10.1017/S0140525X0999152X 
Imhoff, R., \& Erb, H. (2009). What motivates nonconformity? Uniqueness seeking blocks majority influence. Personality and Social Psychology Bulletin, 35, 309-320. doi: $10.1177 / 0146167208328166$

Imhoff, R., \& Lamberty, P. (2017). Too special to be duped: Need for uniqueness motivates conspiracy beliefs. European Journal of Social Psychology, 47(6), 724734. doi: 10.1002/ejsp. 2265

Jolley, D., Douglas, K. (2014). The Effects of Anti-Vaccine Conspiracy Theories on Vaccination Intentions. PLoS ONE, 9(2), e89177. doi: 10.1371/journal.pone.0089177.

Kahan, D. (2016). The politically motivated reasoning paradigm, part 1: What politically motivated reasoning is and how to measure it. In R. Scott \& S. Kosslyn (Eds), Emerging trends in the social and behavioral sciences: An interdisciplinary, searchable, and linkable resource, (pp. 1-16). Hoboken: John Wiley \& Sons. doi: 10.1002/9781118900772.etrds0417.

Lantian, A., Muller, D., Nurra, C., \& Douglas, K. (2017). "I know things they don’t know!": The role of need for uniqueness in belief in conspiracy theories. Social Psychology, 48(3), 160-173. doi: 10.1027/1864-9335/a000306

Lewandowsky, S., Cook, J., \& Lloyd, E. (2018). The 'Alice in Won derland' mechanics of the rejection of (climate) science: simulating coherence by conspiracism. Synthese, 195, 175-196.

Lindeman, M., Svedholm-Hakkinen, A. M., \& Lipsanen, J. (2015). Ontological confusions but not mentalizing abilities predict religious belief, paranormal belief, and belief in supernatural purpose. Cognition, 134,63-76. 
Lobato, E., Mendoza, J., Sims, V., \& Chin, M. (2014). Examining the Relationship Between Conspiracy Theories, Paranormal Beliefs, and Pseudoscience Acceptance Among a University Population. Applied Cognitive Psychology, 28(5), 617-625. doi: 10.1002/acp.3042

Lynn, M., \& Harris, J. (1997). Individual Differences in the Pursuit of Self-Uniqueness Through Consumption. Journal of Applied Social Psychology, 27(21), 1861-1883. doi: 10.1111/j.1559-1816.1997.tb01629.x

Pennycook, G., Cheyne, J., Barr, N., Koehler, D., \& Fugelsang, J. (2015). On the reception and detection of pseudo-profound bullshit. Judgment and Decision Making, 10(6), 549-563.

Pennycook, G., Cheyne, J., Seli, P., Koehler, D., \& Fugelsang, J. (2012). Analytic cognitive style predicts religious and paranormal belief. Cognition, 123(3), 335346. doi: 10.1016/j.cognition.2012.03.003

Saris, W. Satorra, A., \& van der Veld, W. (2009). Testing Structural Equation Models or Detection of Misspecifications?. Structural Equation Modeling: A Multidisciplinary Journal, 16(4), 561-582. doi: 10.1080/10705510903203433

Tabachnick, B., \& Fidell, L. (2007). Using Multivariate Statistics. New York: Pearson.

Tobacyk J (2004) A Revised Paranormal Belief Scale. International Journal of Transpersonal Studies, 23(1), 94-98. doi: 10.24972/ijts.2004.23.1.94

Torres, M., Barberia, I., \& Rodríguez-Ferreiro, J. (2020). Causal illusion as a cognitive basis of pseudoscientific beliefs. British Journal of Psychology, 111(4), 840-852. doi: 10.1111/bjop.12441 
Uscinski, J., Douglas, K., \& Lewandowsky, S. (2017). Climate change conspiracy theories. In H. Von Storch (Ed.), Oxford Research Encyclopedia of Climate Science. Oxford: Oxford University Press. doi: 10.1093/acrefore/9780190228620.013.328. 